\title{
Interaction between low tidal volume ventilation strategy and severity of acute respiratory distress syndrome: a retrospective cohort study
}

\author{
Yanfei Shen ${ }^{1 *+}$ (D), Guolong Cai ${ }^{1 \dagger}$, Shijin Gong ${ }^{1}$, Lei Dong ${ }^{2}$, Jing Yan ${ }^{1}$ and Wanru Cai ${ }^{2}$
}

\begin{abstract}
Background: Although low tidal volume is strongly recommended for acute respiratory distress syndrome (ARDS), whether or not the benefit varies according to the severity of ARDS remains unclear. This study aimed to investigate whether or not there is an interaction between low tidal volume and severity of ARDS.

Methods: This was a secondary analysis from a randomized controlled trial. The patients were subgrouped according to whether the $\mathrm{PaO}_{2} / \mathrm{FiO}_{2}$ (P/F) was $>150$ or $\leq 150 \mathrm{mmHg}$ on day 0 . The interaction between a tidal volume of $6 \mathrm{~mL} / \mathrm{kg}$ and the P/F was investigated in hierarchical chi-square analysis and logistic regression models.

Results: Eight hundred and thirty-six patients with ARDS were enrolled (345 in the high P/F subgroup [> $150 \mathrm{mmHg}$ ] and 491 in the low P/F subgroup [ $\leq 150 \mathrm{mmHg}]$ ). Compared to the traditional tidal volume group, the mortality of patients with low tidal volume was significantly lower in the high P/F subgroup (41/183 (22.4\%) vs. 64/162 (39.5\%), $p=0.001$ ) but not in the low P/F subgroup (95/256 (37.1\%) vs. 96/235 (40.8\%), $p=0.414)$. In the hierarchical chi-square analysis, the test of homogeneity was significant (risk ratio of mortality 0.56 [0.40-0.79] vs. $0.91[0.73-1.13], p=0.018$ ). In the multivariable logistic model, the odds ratio of mortality for the interacted item was significant $(2.02,95 \%$ confidence interval $[\mathrm{Cl}] 1.06-3.86, p=0.033$ ). The odds ratio of mortality for low tidal volume was significant in the high $\mathrm{P} / \mathrm{F}$ subgroup $(0.42,95 \% \mathrm{Cl} 0.24-0.72, p=0.002)$ but not in the low P/F subgroup $(0.89,95 \% \mathrm{Cl} 0.60-1.31, p=0.554)$.
\end{abstract}

Conclusions: The benefits of low tidal volume ventilation remain uncertain in patients with severe ARDS. Further studies are needed to validate this significant interaction.

Keywords: Acute respiratory distress syndrome, Low tidal volume, Mortality, $\mathrm{PaO}_{2} / \mathrm{FiO}_{2}$

\section{Background}

Acute respiratory distress syndrome (ARDS) is a devastating subtype of acute respiratory failure that presents as severe hypoxemia and bilateral pulmonary infiltrates. Globally, it affects more than 3 million patients annually and the overall mortality remains as high as $30-40 \%$ [1]. The cornerstone of management for ARDS is mechanical ventilation, with the aim of minimizing ventilatorinduced lung injury (VILI). In 2000, a landmark trial

\footnotetext{
* Correspondence: snow.shen@hotmail.com

${ }^{\dagger}$ Yanfei Shen and Guolong Cai contributed equally to this work and are listed as co-first authors.

'Department of Intensive Care, Zhejiang Hospital, No. 12, Linyin Road, Hangzhou 310000, Zhejiang, People's Republic of China

Full list of author information is available at the end of the article
}

from the ARDS Network [2] demonstrated that a low tidal volume using $6 \mathrm{~mL} / \mathrm{kg}$ of predicted body weight (PBW) with a target plateau pressure below $30 \mathrm{cmH}_{2} \mathrm{O}$ significantly reduced the mortality rate when compared with a traditional tidal volume strategy $(12 \mathrm{~mL} / \mathrm{kg}$ PBW). Subsequently, the results of other randomized controlled trials (RCTs) and meta-analyses [3-5] have demonstrated the efficacy of a low tidal volume strategy in reducing mortality in ARDS.

However, most of the previous studies [2, 6-9] have focused mainly on the efficacy of a reduced ventilation strategy in ARDS, and it has been unclear whether or not this benefit would be influenced by the severity of ARDS. Terragni et al. [10] found that patients with ARDS

(C) The Author(s). 2019 Open Access This article is distributed under the terms of the Creative Commons Attribution 4.0 International License (http://creativecommons.org/licenses/by/4.0/), which permits unrestricted use, distribution, and 
and lungs with larger collapsed areas were more prone to VILI despite a tidal volume limitation of $6 \mathrm{~mL} / \mathrm{kg}$ PBW than those who had lungs with smaller areas of collapse, which was partly caused by an uneven distribution of tidal volume because the normal alveoli are more prone to distention than those that are collapsed. This raised the important but uninvestigated question of how much benefit patients with severe ARDS can derive from a tidal volume ventilation of $6 \mathrm{~mL} / \mathrm{kg}$ PBW. Furthermore, we noticed in the RCTs reporting a negative effect of a low tidal volume ventilation strategy in ARDS $[6,7]$ that the baseline $\mathrm{PaO}_{2} / \mathrm{FiO}_{2}(\mathrm{P} / \mathrm{F})$ value was significantly lower in the low tidal volume group (150 vs. 129 in the study by Brower et al. [6] and 145 vs. 123 in the study by Stewart et al. [7]). The reason underlying these inconsistent results remains unclear. However, they would be explicable if patients with severe ARDS do not actually benefit from ventilation with a tidal volume of $6 \mathrm{~mL} / \mathrm{kg}$. Accordingly, we performed a second analysis to investigate the interaction effect between ventilation with a low tidal volume and disease severity in patients with ARDS.

\section{Methods}

\section{Data source}

This was a secondary analysis of a prospective RCT [2] that was performed in 10 centers within the Acute Respiratory Distress Syndrome Network of the National Heart, Lung, and Blood Institute research network. The dataset included data for 902 patients, including 861 patients who were randomized to either 6 or $12 \mathrm{ml} / \mathrm{kg}$ in the tidal volume trial and an additional 41 patients who received $6 \mathrm{~mL} / \mathrm{kg}$ in a study that compared lisofylline with placebo. The original study was approved by the institutional review board at each study center, and informed consent was obtained from the patients or their surrogates. All the data used in this study were approved by the Biologic Specimen and Data Repository Information Coordinating Center (BioLINCC, https:// biolincc.nhlbi.nih.gov). The present study was approved by the institutional review board of Dongyang People's Hospital. All the information was de-identified in the downloaded dataset.

\section{Inclusion and exclusion criteria}

Patients under invasive mechanical ventilation support were screened if they met the following Berlin criteria: an acute decrease in the ratio of partial pressure of arterial oxygen to fraction of inspired oxygen $(\mathrm{P} / \mathrm{F})$ to $\leq 300$, bilateral pulmonary infiltrates on a chest radiograph, and no clinical evidence of left atrial hypertension or a pulmonary capillary wedge pressure $\leq 18 \mathrm{mmHg}$. Patients were excluded if they were younger than 18 years of age, if they had participated in another trial in the 30 days before screening, if they were pregnant, or if they had other clinical conditions that could impair breathing or aggravate their clinical condition, such as neuromuscular disease, severe chronic respiratory disease, and high intracranial pressure (that may be worsened by hypercapnia). A detailed description of the inclusion and exclusion criteria is available in the original report [2].

\section{Data extraction}

Demographic data, including age, body mass index, sex, and ethnicity, were collected, as well as information on comorbidities, such as diabetes, immunosuppression, and leukemia. Biochemical measurements, including white blood cell count, platelet count, serum creatinine, albumin, sodium, and bilirubin, and the plasma glucose level were also extracted. Other variables, such as fluid balance, radiographic acute lung injury (ALI) score, pneumothorax, and the $\mathrm{P} / \mathrm{F}$, were recorded. Given that the aim of the study was to investigate the interaction between $\mathrm{P} / \mathrm{F}$ and low tidal volume ventilation in ARDS, two versions of the $\mathrm{P} / \mathrm{F}$ value at different time points were used for robustness, i.e., the $\mathrm{P} / \mathrm{F}$ at the time of screening, which was recorded at the time of screening in ICUs with mechanical ventilation and settings selected by clinicians, and on day 0 of the original trial which was recorded on the first day of the original trial with protocolized ventilator settings. The sensitivity analysis was performed using the $\mathrm{P} / \mathrm{F}$ value at the time of screening. For accuracy, the missing $\mathrm{P} / \mathrm{F}$ value was not inputted and patients without a P/F on day 0 were excluded.

\section{Definition of ventilation procedures}

The original study compared the effect of low and traditional tidal volume in ARDS. In the traditional group, the tidal volume was set at $12 \mathrm{~mL} / \mathrm{kg}$ PBW with a target plateau pressure (airway pressure measured after a 0.5-s pause at the end of inspiration) set at $\leq 50 \mathrm{cmH}_{2} \mathrm{O}$ by stepwise reduction of tidal volume $(1 \mathrm{~mL} / \mathrm{kg}$ PBW per decrement) if necessary. In the low tidal volume group, the tidal volume was set at $6 \mathrm{~mL} / \mathrm{kg} \mathrm{PBW}$ with the plateau pressure at $\leq 30 \mathrm{cmH}_{2} \mathrm{O}$ by stepwise reduction of the tidal volume $(1 \mathrm{~mL} / \mathrm{kg}$ PBW per decrement) if necessary. The minimal tidal volume was $4 \mathrm{~mL} / \mathrm{kg} \mathrm{PBW}$. The volume assist control mode was used in the two groups until weaning or 28 days after randomization, whichever came first. All other ventilation procedures, including weaning, were identical in the two groups. A more detailed description is available in the original report [2].

\section{Study endpoint}

In the original study, the endpoints were divided into three categories: (1) the proportion of patients who went home with unassisted breathing, (2) the proportion of patients who died before discharge to home with 
unassisted breathing or died before achieving unassisted breathing for $48 \mathrm{~h}$, and (3) the proportion of patients meeting neither of these two conditions. The patient status was checked at intervals of $\leq 30$ days until condition 1 or 2 occurred, with a maximum duration of 180 days. Patients who met condition 2 were reported as nonsurvivors, and those who met the other conditions were reported as survivors.

\section{Statistical analysis}

Continuous variables were expressed as the mean \pm standard deviation or median (interquartile range) as appropriate. The Student's $t$ test and Wilcoxon rank-sum test were used as appropriate. Categorical data were expressed as proportions and compared using the chi-square test. The included patients were divided into two subgroups according to whether or the $\mathrm{P} / \mathrm{F}$ value on day 0 was $>150 \mathrm{mmHg}$ or $\leq 150 \mathrm{mmHg}$. Hierarchical chi-square analysis was used to test for homogeneity between the two subgroups. Multivariable logistic regression was used for covariate adjustment. The logistic models were built using the stepwise backward method as follows. First, variables identified to have a $p$ value less than 0.20 in the univariate analysis were included for further multivariable analysis. Nine covariables were identified in this step: age, maximum respiratory rate, immunosuppression, leukemia, radiographic ALI score, lowest platelet count, highest creatinine level, and fluid balance. Next, we used a stepwise backward elimination method to remove variables with a $p$ value $>0.1$ (serum creatinine was removed in this step). Multicollinearity was tested using the variance inflation factor (VIF) method (the radiographic ALI score had a VIF $\geq 5$ so was removed). Goodness of fit tests were applied to all logistic regression models. The interaction effect between the $\mathrm{P} / \mathrm{F}$ and low tidal volume was tested by adding an interacted item ( $\mathrm{P} / \mathrm{F}$ * low tidal volume) in the above model. Predictive marginal effects of low tidal volume were estimated for interpretation at different $\mathrm{P} /$ $F$ values on day 0 . A two-tailed test was performed, and a $p$ value $<0.05$ was considered statistically significant. All statistical analyses were performed using Stata 11.2 (StataCorp, College Station, TX, USA).

\section{Results}

Data for 902 patients were available in the dataset downloaded from BioLINCC. The P/F value on day 0 was missing in 66 patients, so these patients were excluded from the analysis. Finally, 836 patients (540 survivors and 296 non-survivors) were included in the study. These patients were divided into two subgroups according to whether or not their $\mathrm{P} / \mathrm{F}$ on day 0 was $>150 \mathrm{mmHg}$ (the high $\mathrm{P} / \mathrm{F}$ subgroup, $n=345$ ) or $\leq 150 \mathrm{mmHg}$ (the low $\mathrm{P} / \mathrm{F}$ subgroup, $n=491)$. No significant differences were detected in the demographics or in the physical or biochemical parameters at baseline, so the characteristics of the group that underwent a low tidal volume procedure and those of the group that underwent a traditional tidal volume procedure were considered well balanced (Table 1).

The baseline $\mathrm{P} / \mathrm{F}$ value on day 0 was also similar between the two tidal volume groups $(212.2 \pm 65.2$ vs. $210.6 \pm 56.0$ in the high P/F subgroup, $p=0.817 ; 103.2 \pm$ 26.7 vs. $104.2 \pm 26.5$ in the low $\mathrm{P} / \mathrm{F}$ subgroup, $p=0.684$ ). Therefore, hierarchical chi-square analysis was used to evaluate the effect of low tidal volume in these two subgroups. Compared to the traditional tidal volume group, the mortality of patients with low tidal volume was significantly lower in the high P/F subgroup (41/183 (22.4\%) vs. 64/162 (39.5\%), $p=0.001$ ) but not in the low $\mathrm{P} / \mathrm{F}$ subgroup (95/256 (37.1\%) vs. $96 / 235(40.8 \%), p=0.414)$. In the hierarchical chi-square analysis, the test for homogeneity for the risk ratio of mortality in these two subgroups was significant $(0.56$ [0.40-0.79] vs. 0.91 [0.73-1.13], $p=0.018$ ) (Table 2).

Given the retrospective nature of the research, there remained a risk that this finding was biased by unadjusted covariables. Therefore, multivariable logistic regression was applied for adjustment, and the interactive effect was evaluated by adding the interacted item $(\mathrm{P} / \mathrm{F} *$ low tidal volume) in the model. The odds ratio of mortality for the interacted item was significant $(2.02,95 \%$ confidence interval $[\mathrm{CI}] 1.06-3.86, p=0.033$; in Additional file 1: Table S1), suggesting a P/F-dependent effect of low tidal volume. In the subgroup analysis (Table 3), the odds ratio of mortality for low tidal volume was significant in the high $\mathrm{P} / \mathrm{F}$ subgroup $(0.42,95 \% \mathrm{CI} 0.24-0.72, p=0.002)$ but not in the low $\mathrm{P} / \mathrm{F}$ subgroup $(0.89,95 \%$ CI $0.60-1.31$, $p=0.554)$. The predicted marginal effect on mortality of low tidal volume was also estimated at different $\mathrm{P} / \mathrm{F}$ values on day $0(40,60,80,100,120,140,160$, $180,200,220,240,260,280)$ in Fig. 1. The difference in the probability of mortality between the traditional and low tidal volume groups increased with increasing $\mathrm{P} / \mathrm{F}$ on day 0 , which was consistent with the previous findings.

Eight hundred and thirty-one patients were included in the sensitivity analysis using the $\mathrm{P} / \mathrm{F}$ value at screening, and the results were similar to the main finding that the effect on mortality of low tidal volume was significant in patients with a $\mathrm{P} / \mathrm{F}>150 \mathrm{mmHg}(43 / 110$ (39.1\%) vs. $32 / 145(22.1 \%), p=0.003)$ but not in patients with a $\mathrm{P} / \mathrm{F} \leq 150 \mathrm{mmHg}(116 / 285$ (40.7\%) vs. $104 / 291$ (35.7), $p=0.220$ ). However, only 255 patients were included in the high $\mathrm{P} / \mathrm{F}$ subgroup, and the $p$ value for homogeneity was less significant $(0.047$ in the hierarchical chi-square analysis and 0.064 in the logistic model, in Additional file 1: Tables S2 and S3, respectively). 
Table 1 Comparison of baseline characteristics between the traditional and low tidal volume subgroups

\begin{tabular}{|c|c|c|c|c|c|c|}
\hline \multirow[t]{2}{*}{ Variables } & \multicolumn{2}{|c|}{ Subgroup with $\mathrm{PaO}_{2} / \mathrm{FiO}_{2}>150$} & \multirow[b]{2}{*}{$p$ value } & \multicolumn{2}{|c|}{ Subgroup with $\mathrm{PaO}_{2} / \mathrm{FiO}_{2} \leq 150$} & \multirow[b]{2}{*}{$p$ value } \\
\hline & $\begin{array}{l}\text { Traditional tidal } \\
\text { volume }(n=162)\end{array}$ & $\begin{array}{l}\text { Low tidal } \\
\text { volume }(n=183)\end{array}$ & & $\begin{array}{l}\text { Traditional tidal } \\
\text { volume }(n=235)\end{array}$ & $\begin{array}{l}\text { Low tidal } \\
\text { volume }(n=256)\end{array}$ & \\
\hline Age (years) & $50.3 \pm 18.5$ & $50.8 \pm 16.8$ & 0.800 & $52.5 \pm 17.3$ & $50.7 \pm 16.6$ & 0.233 \\
\hline Male $[n(\%)]$ & 95 (58.6) & $117(63.9)$ & 0.317 & $138(58.7)$ & $148(57.8)$ & 0.838 \\
\hline BMI $\left(\mathrm{kg} / \mathrm{m}^{2}\right)$ & $27.2 \pm 7.0$ & $27.4 \pm 7.6$ & 0.803 & $26.8 \pm 6.4$ & $27.4 \pm 6.59$ & 0.273 \\
\hline Ethnicity (White, \%) & $119(73.4)$ & $138(75.4)$ & 0.678 & $162(68.9)$ & $190(74.2)$ & 0.194 \\
\hline Ethnicity (Black, \%) & $31(19.1)$ & $28(15.3)$ & 0.345 & $42(17.8)$ & $41(16.0)$ & 0.583 \\
\hline \multicolumn{7}{|l|}{ Comorbidities } \\
\hline Chronic dialysis [n (\%)] & $6(3.7)$ & $3(1.6)$ & 0.226 & $4(1.7)$ & $6(2.3)$ & 0.620 \\
\hline Leukemia [n (\%)] & $4(2.4)$ & $3(1.6)$ & 0.579 & $5(2.1)$ & $7(2.7)$ & 0.669 \\
\hline Immunosuppression [n (\%)] & $17(10.4)$ & $13(7.1)$ & 0.256 & $24(10.2)$ & $32(12.6)$ & 0.436 \\
\hline Diabetes $[n(\%)]$ & $22(13.5)$ & 25 (13.6) & 0.997 & $33(14.0)$ & $36(14.0)$ & 0.973 \\
\hline Elective surgery $[n(\%)]$ & $12(7.4)$ & $17(9.2)$ & 0.520 & $18(7.6)$ & $26(10.1)$ & 0.371 \\
\hline $\begin{array}{l}\text { Radiographic ALI score } \\
\text { median (IQR) }\end{array}$ & $4(3-4)$ & $4(3-4)$ & 0.671 & $4(4-4)$ & $4(4-4)$ & 0.650 \\
\hline Pneumothoraces [n (\%)] & $12(7.4)$ & $16(8.7)$ & 0.687 & $44(18.7)$ & 35 (13.6) & 0.117 \\
\hline Chest tube $[n(\%)]$ & $42(25.9)$ & $38(20.7)$ & 0.218 & $57(24.2)$ & $71(27.7)$ & 0.412 \\
\hline \multicolumn{7}{|l|}{ Parameters on screen } \\
\hline $\mathrm{PaO}_{2} / \mathrm{FiO}_{2}(\mathrm{mmHg})$ & $161.5 \pm 59.2$ & $165.0 \pm 65.8$ & 0.601 & $103.8 \pm 39.1$ & $107.2 \pm 41.6$ & 0.358 \\
\hline $\mathrm{PaO}_{2}(\mathrm{mmHg})$ & $103.9 \pm 49.2$ & $101.7 \pm 43.5$ & 0.677 & $81.4 \pm 32.4$ & $79.1 \pm 27.8$ & 0.400 \\
\hline \multicolumn{7}{|c|}{ Indexes within 24-h preceding trial } \\
\hline Maximum respiratory rate & $31.3 \pm 12.4$ & $28.9 \pm 10.0$ & 0.053 & $30.5 \pm 10.7$ & $30.8 \pm 10.7$ & 0.748 \\
\hline $\begin{array}{l}\text { Minimum mean blood } \\
\text { pressure }(\mathrm{mmHg})\end{array}$ & $63.5 \pm 14.3$ & $63.7 \pm 14.2$ & 0.862 & $61.1 \pm 13.5$ & $59.8 \pm 11.1$ & 0.220 \\
\hline $\begin{array}{l}\text { Maximum serum creatinine } \\
(\mathrm{mg} / \mathrm{dL})\end{array}$ & $1.76 \pm 1.68$ & $1.76 \pm 1.47$ & 0.979 & $1.75 \pm 1.61$ & $1.54 \pm 1.37$ & 0.129 \\
\hline $\begin{array}{l}\text { Minimum platelet count } \\
\left(10^{9} / \mathrm{L}\right)\end{array}$ & $154.3 \pm 108.9$ & $145.7 \pm 98.7$ & 0.439 & $157.9 \pm 108.9$ & $176.6 \pm 135.2$ & 0.094 \\
\hline $\begin{array}{l}\text { Maximum white blood cell } \\
\left(10^{9} / \mathrm{L}\right)\end{array}$ & $15.6 \pm 10.6$ & $14.5 \pm 8.8$ & 0.272 & $14.6 \pm 8.9$ & $15.2 \pm 11.8$ & 0.587 \\
\hline \multicolumn{7}{|l|}{$\begin{array}{l}\text { Parameters on day } 0 \text { of } \\
\text { the trial }\end{array}$} \\
\hline Fluid intake (mL) & $5217.7 \pm 3782.1$ & $5065.2 \pm 4070.9$ & 0.719 & $4896.0 \pm 4045.2$ & $5366.1 \pm 4293.9$ & 0.213 \\
\hline Fluid output (mL) & $2374.0 \pm 1716.2$ & $2473.2 \pm 1698.6$ & 0.590 & $2375.6 \pm 1694.9$ & $2396.8 \pm 1630.3$ & 0.887 \\
\hline $\mathrm{PaO}_{2} / \mathrm{FiO}_{2}(\mathrm{mmHg})$ & $212.2 \pm 65.2$ & $210.6 \pm 56.0$ & 0.817 & $103.2 \pm 26.7$ & $104.2 \pm 26.5$ & 0.684 \\
\hline PEEP on day $0\left(\mathrm{cmH}_{2} \mathrm{O}\right)$ & $7.4 \pm 3.8$ & $7.4 \pm 3.2$ & 0.999 & $8.9 \pm 3.9$ & $9.5 \pm 3.9$ & 0.109 \\
\hline PEEP on day $1\left(\mathrm{cmH}_{2} \mathrm{O}\right)$ & $6.5 \pm 3.2(n=162)$ & $6.8 \pm 2.3(n=179)$ & 0.294 & $9.6 \pm 3.3(n=233)$ & $11.1 \pm 3.7(n=251)$ & $<0.001$ \\
\hline $\begin{array}{l}\text { Plateau pressures on } \\
\text { day } 1\left(\mathrm{cmH}_{2} \mathrm{O}\right)\end{array}$ & $28.8 \pm 7.6(n=125)$ & $27.3 \pm 7.3(n=137)$ & 0.086 & $31.6 \pm 8.2(n=186)$ & $31.6 \pm 7.6(n=211)$ & 0.975 \\
\hline $\begin{array}{l}\text { Plateau pressures on } \\
\text { day } 2\left(\mathrm{cmH}_{2} \mathrm{O}\right)\end{array}$ & $30.6 \pm 8.4(n=146)$ & $22.5 \pm 5.8(n=151)$ & $<0.001$ & $33.7 \pm 8.6(n=223)$ & $26.4 \pm 6.4(n=239)$ & $<0.001$ \\
\hline $\begin{array}{l}\text { Driving pressure on day } 1 \\
\left(\mathrm{CmH}_{2} \mathrm{O}\right)\end{array}$ & $21.6 \pm 6.9(n=125)$ & $19.7 \pm 6.9(n=137)$ & 0.027 & $22.6 \pm 7.2(n=186)$ & $21.8 \pm 6.7(n=211)$ & 0.276 \\
\hline $\begin{array}{l}\text { Driving pressure on day } 2 \\
\left(\mathrm{CmH}_{2} \mathrm{O}\right)\end{array}$ & $23.9 \pm 7.2(n=146)$ & $15.4 \pm 5.3(n=151)$ & $<0.001$ & $23.9 \pm 7.3(n=223)$ & $15.3 \pm 5.3(n=239)$ & $<0.001$ \\
\hline
\end{tabular}


Table 2 Crude outcomes and test of homogeneity in the traditional and low tidal volume subgroups

\begin{tabular}{|c|c|c|c|c|c|c|}
\hline \multirow[t]{2}{*}{ Variables } & \multicolumn{3}{|l|}{$\begin{array}{l}\text { Subgroup with } \\
\mathrm{PaO}_{2} / \mathrm{FiO}_{2}>150\end{array}$} & \multicolumn{2}{|c|}{ Subgroup with $\mathrm{PaO}_{2} / \mathrm{FiO}_{2} \leq 150$} & \multirow[b]{2}{*}{$p$} \\
\hline & $\begin{array}{l}\text { Traditional tidal } \\
\text { volume }(n=162)\end{array}$ & $\begin{array}{l}\text { Low tidal } \\
\text { volume }(n=183)\end{array}$ & $p$ & $\begin{array}{l}\text { Traditional tidal } \\
\text { volume }(n=235)\end{array}$ & $\begin{array}{l}\text { Low tidal } \\
\text { volume }(n=256)\end{array}$ & \\
\hline $\begin{array}{l}\text { Patients achieving unassisted breathing } \\
\text { for } 48 \mathrm{~h}[\mathrm{n}(\%)]\end{array}$ & $96(59.2)$ & $141(77.0)$ & $<0.001$ & $119(50.6)$ & $151(58.9)$ & 0.063 \\
\hline $\begin{array}{l}\text { Death before discharge home and breathing } \\
\text { without assistance }[n(\%)]\end{array}$ & $64(39.5)$ & $41(22.4)$ & 0.001 & $96(40.8)$ & $95(37.1)$ & 0.414 \\
\hline Risk ratio of death ${ }^{\#}$ & $0.56(0.40-0.79)$ & & & $0.91(0.73-1.13)$ & & \\
\hline
\end{tabular}

\#The risk ratio was calculated using hierarchical chi-square analysis, and the $p$ value for homogeneity (Mantel-Haenszel) was 0.0185

\section{Discussion}

The main finding of our study is the significant interaction between low tidal volume ventilation and oxygenation in patients with ARDS. In patients with a P/F $>150 \mathrm{mmHg}$, a ventilation strategy that included a tidal volume of $6 \mathrm{~mL} / \mathrm{kg}$ PBW with a target plateau pressure at $30 \mathrm{cmH}_{2} \mathrm{O}$ resulted in an absolute $17.1 \%$ reduction in mortality; however, the benefit may have been weakened in patients with a P/F value $\leq 150 \mathrm{mmHg}$. Despite the efficacy of the low tidal volume strategy having already been investigated in many studies, our finding proposes a new but important concept that needs to be investigated further.

Whether or not use of lower tidal volume ventilation can reduce the risk of VILI has been investigated for the past 30 years, which is recommended in the current ARDS consensus [11, 12]. However, the extent to which tidal volume and inspiratory airway pressure should be reduced to optimize clinical outcomes remains controversial. Most of the previous trials focused on the efficacy of a reduced tidal volume strategy in patients with ARDS, and whether or not this benefit would be influenced by the severity of ARDS has remained unclear. However, the previous research demonstrated a heterogeneous distribution of pulmonary alterations in ARDS on computed tomography images, such as hyperinflated, normally aerated, and nonaerated compartments $[13,14]$, which were associated with different clinical outcomes [15]. Pathophysiologically, this heterogeneity may lead to an uneven distribution of tidal volume, given that the nonaerated compartments would be stiffer than the other compartments and have decreased compliance. Consequently, alveoli in the relatively normally aerated area are prone to more hyperinflation than other areas, which may play a role in the mechanism of VILI. Involvement of alveoli in normally aerated areas in the mechanism is consistent with the finding by Terragni et al. [10] that patients with ARDS with more nonaerated compartments were more likely to develop VILI than those with fewer nonaerated compartments. Furthermore, this phenomenon is also partly explained by our finding that the benefit of $6 \mathrm{~mL} / \mathrm{kg}$ PBW ventilation may be reduced in patients with low $\mathrm{P} / \mathrm{F}$ because a low $\mathrm{P} / \mathrm{F}$ to a certain extent represents more severe lung status and may be associated with more nonaerated compartments in which VILI may be more likely to occur. On the other hand, Terragni et al. [16] also found that the risk of tidal hyperinflation and pulmonary inflammation was lower with an ultra-low tidal volume strategy $(4 \mathrm{ml} / \mathrm{kg} \mathrm{PBW})$ than with the $6 \mathrm{~mL} / \mathrm{kg}$ PBW ventilation strategy but could be accompanied by development of severe respiratory acidosis necessitating extracorporeal carbon dioxide removal [2]. Given that removal of extracorporeal carbon dioxide in all patients with ARDS would be clinically impracticable, identifying

Table 3 Multivariable logistic regression in the traditional and low tidal volume subgroups

\begin{tabular}{|c|c|c|c|c|}
\hline \multirow[t]{2}{*}{ Variables } & \multicolumn{2}{|c|}{$\begin{array}{l}\text { Model } 1 \\
\text { Subgroup with } \mathrm{PaO}_{2} / \mathrm{FiO}_{2}>150(n=345)\end{array}$} & \multicolumn{2}{|c|}{$\begin{array}{l}\text { Model } 2 \\
\text { Subgroup with } \mathrm{PaO}_{2} / \mathrm{FiO}_{2} \leq 150(n=491)\end{array}$} \\
\hline & Adjusted odds ratio $(95 \% \mathrm{Cl})$ & $p$ & Adjusted odds ratio $(95 \% \mathrm{Cl})$ & p \\
\hline Low tidal volume & $0.42(0.24-0.72)$ & 0.002 & $0.88(0.60-1.31)$ & 0.554 \\
\hline Immunosuppression & $3.60(1.38-9.40)$ & 0.009 & $1.42(0.75-2.67)$ & 0.274 \\
\hline Leukemia & $0.87(0.14-5.19)$ & 0.887 & $5.52(1.23-24.8)$ & 0.026 \\
\hline Respiratory rate & $1.02(1.00-1.05)$ & 0.032 & $1.02(1.00-1.04)$ & 0.008 \\
\hline Platelet count $\left(10^{9} / \mathrm{L}\right)$ & $0.99(0.99-0.99)$ & 0.011 & $0.99(0.99-1.00)$ & 0.106 \\
\hline Age (years) & $1.05(1.03-1.06)$ & $<0.001$ & $1.04(1.02-1.05)$ & $<0.001$ \\
\hline Fluid balance & $1.10(1.04-1.16)$ & 0.001 & $1.05(1.00-1.10)$ & $<0.001$ \\
\hline
\end{tabular}

Note: The $p$ value for interaction item (PaO2/FiO2 * low tidal volume) was 0.033 in Additional file 1: Table S1. The VIF value were 2.91 and 2.82 , and the $p$ values of goodness of fit are 0.479 and 0.355 for model 1 and model 2, respectively 


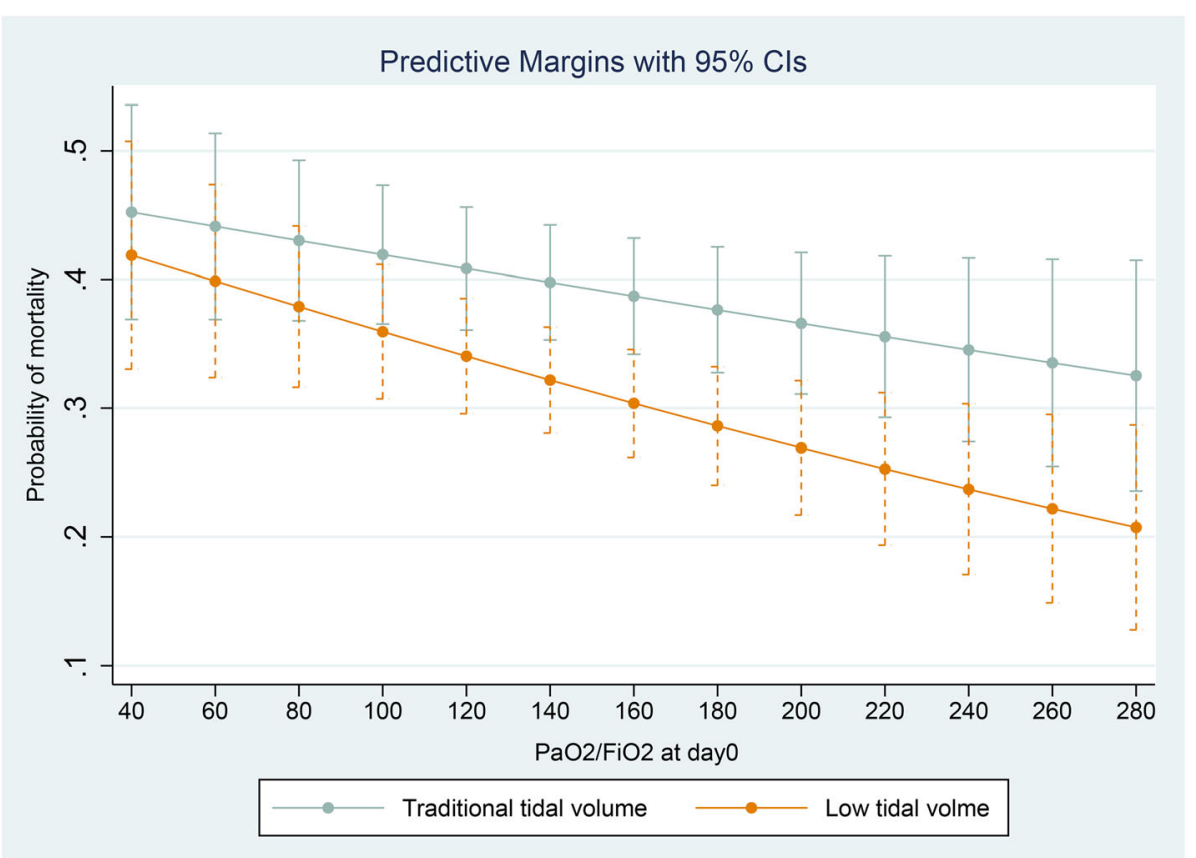

Fig. 1 Predictive marginal effect of low tidal volume strategy at different $\mathrm{PaO}_{2} / \mathrm{FiO}_{2}$ at day $0 . \mathrm{PaO}_{2} / \mathrm{FiO}_{2}$, ratio of partial pressure of arterial oxygen to fraction of inspired oxygen

patients who would or would not benefit from ventilation with a tidal volume of $6 \mathrm{~mL} / \mathrm{kg}$ PBW became critically important. In the present study, we found that a low tidal volume of $6 \mathrm{~mL} / \mathrm{kg}$ PBW had a heterogeneous effect according to the severity of ARDS. Unlike in previous studies, we found that the effect of a low tidal volume of $6 \mathrm{~mL} / \mathrm{kg}$ PBW was uncertain in patients with severe ARDS $(\mathrm{P} / \mathrm{F} \leq 150)$ but was significant in those with mild ARDS. It is possible that the mechanism underlying this interaction is multifactorial. For instance, a larger nonaerated compartment may to some degree represent more severe ARDS that would be associated with a lower P/F. Therefore, in theory, compared with patients with high $\mathrm{P} / \mathrm{F}$, those with low $\mathrm{P} / \mathrm{F}$ may benefit less from a low tidal ventilation strategy because these are the patients who are more likely to develop VILI. If this is the case, the conclusions of previous three RCTs [6-8] that found no significant benefit of low tidal volume in patients with ARDS would be understandable. One common issue in those studies was that the baseline $\mathrm{P} / \mathrm{F}$ value was lower in the low tidal ventilation groups ( 150 vs. 129 in the study by Brower et al. [6], 145 vs. 123 in the study by Stewart et al. [7], and 144 vs. 155 in the study by Brochard et al. [8]). Therefore, the effect of low tidal volume may be weakened in low tidal volume groups, leading to these nonsignificant conclusions.

Several limitations of this study need to be addressed. First, despite the large sample size, the statistical power of the study was significantly weakened by the subgroup analysis. Therefore, the nonsignificant finding in the low $\mathrm{P} / \mathrm{F}$ subgroup needs further investigation. Second, during the last decade, other mechanical parameters, such as transpulmonary pressure and lung compliance, have been reported to be closely associated with clinical outcomes in patients with ARDS. However, these data are lacking in the current study, which increased the risk of bias. For example, transpulmonary pressure and lung compliance may vary more in patients with severe ARDS than in those with mild ARDS, which may offset the benefit of low tidal volume in the severe subgroup. Given the lack of data, the impact of these mechanical properties cannot be inferred from the present study. Third, severe ARDS was defined as $\mathrm{P} / \mathrm{F} \leq 150 \mathrm{mmHg}$ in the current study, and this cut-off value was also adopted in previous studies $[17,18]$. The reason we did not use the Berlin definition (100 $\mathrm{mmHg}$ as the cut-off value) is that the proportion of patients with mild ARDS was very small and not large enough for statistical analysis.

\section{Conclusions}

Our present findings suggest that the effects of a lower tidal volume ventilation strategy $(6 \mathrm{~mL} / \mathrm{kg}$ with a plateau pressure goal of $30 \mathrm{cmH} 2 \mathrm{O}$ ) may be smaller in patients with more severe ARDS than in those with a P/F $>150 \mathrm{mmHg}$. Further studies that account for all the other factors that might potentially influence the outcome are needed before firm conclusions to be drawn regarding the effects of low tidal volumes. 


\section{Additional file}

Additional file 1: Table S1. Interaction between low tidal volume and $\mathrm{PaO}_{2} / \mathrm{FiO}_{2}$ in multivariable logistic regression. Table S2. Crude outcomes test of homogeneity in the subgroups with high and low $\mathrm{PaO}_{2} / \mathrm{FiO}_{2}$. (DOC 58 kb)

\section{Abbreviations}

ALI: Acute lung injury; ARDS: Acute respiratory distress syndrome; $\mathrm{Cl}$ : Confidence interval; PaO2/FiO2: Partial pressure of arterial oxygen to fraction of inspired oxygen; PBW: Predicted body weight; RCT: Randomized controlled trial; VIF: Variance inflation factor; VILI: Ventilator-induced lung injury

\section{Acknowledgements}

We thank Dr. Caibao Hu from Zhejiang Hospital for his help during the revision process.

\section{Authors' contributions}

YS and GC designed the study and take overall responsibility for its content SG and JY conducted the search and the statistical analysis. LD and WC assessed the study eligibility and quality and interpreted the data. All authors contributed to the manuscript and approved the final version to be considered for publication.

\section{Funding}

G.C. received funding from Zhejiang Province Health High-Level Talents and the Zhejiang Province Sepsis Innovation Project for assistance with the copyediting of the manuscript. WC received funding from the National Natural Science Foundation of China (General Program, 81774220) to conduct this research.

\section{Availability of data and materials}

The datasets presented in the current study are available in the BioLINCC website. (https://biolincc.nhlbi.nih.gov)

\section{Ethics approval and consent to participate}

This was a secondary analysis of a prospective RCT which was approved by the institutional review board at each study center, and informed consent was obtained from the patients or their surrogates. All the information was de-identified in the downloaded dataset. Thus, the ethical approval statement and the need for informed consent were waived for this manuscript.

\section{Consent for publication}

Not applicable.

\section{Competing interests}

The authors declare that they have no competing interests.

\section{Author details}

${ }^{1}$ Department of Intensive Care, Zhejiang Hospital, No. 12, Linyin Road, Hangzhou 310000, Zhejiang, People's Republic of China. ${ }^{2}$ Respiratory Department, The Second Affiliated Hospital of Zhejiang Chinese Medicine University, No. 318, Chaowang Road, Hangzhou 310005, People's Republic of China.

\section{Received: 17 January 2019 Accepted: 26 June 2019}

Published online: 12 July 2019

\section{References}

1. Phua J, Badia JR, Adhikari NK, Friedrich JO, Fowler RA, Singh JM, Scales DC, Stather DR, Li A, Jones A, et al. Has mortality from acute respiratory distress syndrome decreased over time?: a systematic review. Am J Respir Crit Care Med. 2009;179(3):220-7.

2. Acute Respiratory Distress Syndrome N, Brower RG, Matthay MA, Morris A, Schoenfeld D, Thompson BT, Wheeler A. Ventilation with lower tidal volumes as compared with traditional tidal volumes for acute lung injury and the acute respiratory distress syndrome. N Engl J Med. 2000; 342(18):1301-8
3. Putensen C, Theuerkauf N, Zinserling J, Wrigge H, Pelosi P. Meta-analysis: ventilation strategies and outcomes of the acute respiratory distress syndrome and acute lung injury. Ann Intern Med. 2009;151(8):566-76.

4. Fan E, Needham DM, Stewart TE. Ventilatory management of acute lung injury and acute respiratory distress syndrome. Jama. 2005;294(22):2889-96.

5. Petrucci $N$, De Feo C. Lung protective ventilation strategy for the acute respiratory distress syndrome. Cochrane Database Syst Rev. 2013;(2): CD003844.

6. Brower RG, Shanholtz CB, Fessler HE, Shade DM, White P Jr, Wiener CM, Teeter JG, Dodd-o JM, Almog Y, Piantadosi S. Prospective, randomized, controlled clinical trial comparing traditional versus reduced tidal volume ventilation in acute respiratory distress syndrome patients. Crit Care Med. 1999:27(8):1492-8.

7. Stewart TE, Meade MO, Cook DJ, Granton JT, Hodder RV, Lapinsky SE, Mazer CD, McLean RF, Rogovein TS, Schouten BD, et al. Evaluation of a ventilation strategy to prevent barotrauma in patients at high risk for acute respiratory distress syndrome. Pressure- and Volume-Limited Ventilation Strategy Group. N Engl J Med. 1998;338(6):355-61.

8. Brochard L, Roudot-Thoraval F, Roupie E, Delclaux C, Chastre J, FernandezMondejar E, Clementi E, Mancebo J, Factor P, Matamis D, et al. Tidal volume reduction for prevention of ventilator-induced lung injury in acute respiratory distress syndrome. The Multicenter Trail Group on tidal volume reduction in ARDS. Am J Respir Crit Care Med. 1998;158(6):1831-8.

9. Amato MB, Barbas CS, Medeiros DM, Magaldi RB, Schettino GP, Lorenzi-Filho G, Kairalla RA, Deheinzelin D, Munoz C, Oliveira R, et al. Effect of a protective-ventilation strategy on mortality in the acute respiratory distress syndrome. N Engl J Med. 1998;338(6):347-54.

10. Terragni PP, Rosboch G, Tealdi A, Corno E, Menaldo E, Davini O, Gandini G, Herrmann P, Mascia L, Quintel M, et al. Tidal hyperinflation during low tidal volume ventilation in acute respiratory distress syndrome. Am J Respir Crit Care Med. 2007;175(2):160-6.

11. Fan E, Del Sorbo L, Goligher EC, Hodgson CL, Munshi L, Walkey AJ, Adhikari NKJ, Amato MBP, Branson R, Brower RG, et al. An official American Thoracic Society/European Society of Intensive Care Medicine/Society of Critical Care Medicine clinical practice guideline: mechanical ventilation in adult patients with acute respiratory distress syndrome. Am J Respir Crit Care Med. 2017:195(9):1253-63.

12. Del Sorbo L, Goligher EC, McAuley DF, Rubenfeld GD, Brochard LJ, Gattinoni L, Slutsky AS, Fan E. Mechanical ventilation in adults with acute respiratory distress syndrome. Summary of the experimental evidence for the clinical practice guideline. Ann Am Thorac Soc. 2017;14(Supplement_4):S261-70.

13. Gattinoni L, Caironi P, Pelosi P, Goodman LR. What has computed tomography taught us about the acute respiratory distress syndrome? Am J Respir Crit Care Med. 2001;164(9):1701-11.

14. Vieira SR, Puybasset L, Richecoeur J, Lu Q, Cluzel P, Gusman PB, Coriat P, Rouby JJ. A lung computed tomographic assessment of positive endexpiratory pressure-induced lung overdistension. Am J Respir Crit Care Med. 1998:158(5 Pt 1):1571-7.

15. Gattinoni L, Caironi P, Cressoni M, Chiumello D, Ranieri VM, Quintel M, Russo S, Patroniti N, Cornejo R, Bugedo G. Lung recruitment in patients with the acute respiratory distress syndrome. N Engl J Med. 2006;354(17):1775-86.

16. Terragni PP, Del Sorbo L, Mascia L, Urbino R, Martin EL, Birocco A, Faggiano C, Quintel M, Gattinoni L, Ranieri VM. Tidal volume lower than $6 \mathrm{ml} / \mathrm{kg}$ enhances lung protection: role of extracorporeal carbon dioxide removal. Anesthesiology. 2009;111(4):826-35.

17. Guerin C, Reignier J, Richard JC, Beuret P, Gacouin A, Boulain T, Mercier E, Badet $\mathrm{M}$, Mercat $\mathrm{A}$, Baudin $\mathrm{O}$, et al. Prone positioning in severe acute respiratory distress syndrome. N Engl J Med. 2013;368(23):2159-68.

18. Bellani G, Laffey JG, Pham T, Madotto F, Fan E, Brochard L, Esteban A, Gattinoni L, Bumbasirevic V, Piquilloud L, et al. Noninvasive ventilation of patients with acute respiratory distress syndrome. Insights from the LUNG SAFE study. Am J Respir Crit Care Med. 2017;195(1):67-77.

\section{Publisher's Note}

Springer Nature remains neutral with regard to jurisdictional claims in published maps and institutional affiliations. 